\title{
Short Note \\ Wildfire trends in Nepal based on MODIS burnt-area data
}

\author{
S. Khanal ${ }^{1}$
}

$F_{s}$ re, a commonly used traditional tool across South-Asia to support activities such as agricultural land and pasture management, often becomes uncontrolled, escapes those landuse mainly during dry season (Sharma, 2008). Nepal has experienced occasional extreme fire events in recent years including trans-boundary wildfire and haze pollution (GoN, 2010). Fire is recognized as an important ecosystem process globally (Hurteau et al., 2014). Though, fire had a key role in evolution as well as current distribution of current ecosystem, human activities and climate change have resulted in changes in fire regimes globally making some ecosystems more threatened due to altered fire activities (Pausas and Keeley, 2009). In case of Nepal as well, human-induced forest fire is considered as one of the main reasons for changes in forest ecosystems and loss of biodiversity (HMGN/MFSC, 2002).

Wide range of challenges related to institutional, policy and legal frameworks have been identified as lacking for wildfire disaster management in Nepal (GoN/MFSC, 2010). Increasing fire events has been identified as one of the impacts of climate change (GoN/MoE, 2010) and, thus, more frequent and severe fire events can be expected in future. Lack of sufficient fire statistics for Nepal has also been recognized (Bajracharya, 2001). Understanding fire regime is important in order to make decisions regarding fire management. Thus, information such as hot spots of fire activity, the spatio-temporal pattern of fire distribution as well as the total amount of burnt-area across Nepal are some of the essential information for planning and implementing fire management activities. However, detecting as well as monitoring the impact of fire on vegetation over large and often remote geographical area is challenging. Use of satellite data offers a feasible option to monitor forest fire at a national scale as frequent and intense field validation is impractical due to difficult terrain, weather conditions and importantly huge

amount of cost and time involved. Satellitebased observations have been used to quantify spatio-temporal distribution of fire up to global scale (Dwyer et al., 2000; Giglio et al., 2006). In this study, I used MODIS-based estimates of the burnt-area data to examine the spatio-temporal pattern of the fire activity across Nepal.

This study covered the area of Nepal $\left(26^{\circ} 20^{\prime} 53^{\prime \prime}\right.$ $-30^{\circ} 26^{\prime} 51^{\prime \prime} \mathrm{N}$ latitudes and $80^{\circ} 3{ }^{\prime} 30^{\prime \prime}-88^{\circ} 12^{\prime}$ 5" E longitudes). The information on fire activity across Nepal was derived from the MODISbased estimate of the time series burnt-area. The MODIS burnt-area product (MCD45A1 collection 5.1) which is a monthly $500 \mathrm{~m}$ spatial resolution gridded burnt-area product (Boschetti et al., 2009) was used for the purpose. The product is based on bi-directional reflectance (BRDF) model-based change detection approach to map burnt-areas (Roy et al., 2006). The algorithm used detects the approximate date of burn based on the observed changes in daily MODIS reflectance product. Each of the date of burn has associated quality assessment information. Using MODIS package (Matteo et al., 2013), monthly data from the MODIS tiles h24v05, h24v06, h25v05 and h25v06 were downloaded from USGSLPDAAC (United States Geological Survey Land Processes Distributed Active Archive Center), re-projected, clipped and converted to Geotiff format. In this analysis, pixels belonging to all confidence levels (1 to 4 ) were considered.

Since, climate is generally understood as a key parameter in initiating and driving fire events, the burnt-area from MODIS were compared against the climate data. Understanding climatic control on fire regime across Nepal is essential in order to understand the climate-fire relationship as well as for predicting how the fire-hazard may behave in the future with altered climate. The climatic datasets were acquired from World Clim which is a set of global climate layers in the form of $1 \mathrm{~km}$ spatial resolution raster grids (Hijmans et

Department of Forest Research and Survey, Babarmahal, Kathmandu, E-mail: skhanal@dfrs.gov.np 
al., 2005). The monthly average temperature and rainfall layers were downloaded, re-projected and clipped to Nepal extent using raster package (Hijmans, 2015) in R (R Core Team, 2013).

Burn frequency was obtained as a count of how many times a pixel was burnt annually (Figure 1). It is clearly visible that the fire is dominant as well as frequent in the Western Nepal as compared to the Central and the Eastern Nepal. In particular, the fire events are more frequent as well as extensive in the mid-western Churia region. Since, it is recognized that uncontrolled fires can make a serious threat to Churia and higher elevation area (GoN/MFSC, 2014), the results suggest that fire management activity has to put primary focus in this region. The histogram in inset shows the distribution of pixels by their burn frequency. The pixels recorded as burnt more than 10 times during the study period are, in fact, few (less than 50) compared to others.

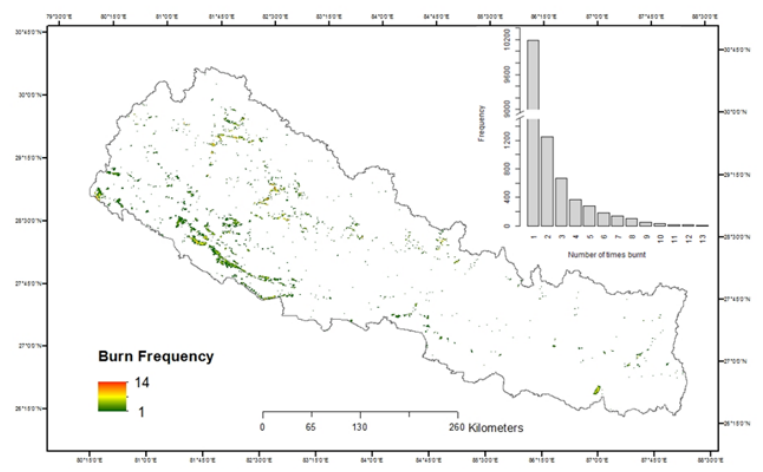

Fig. 1: Map showing the number of times each pixel burnt during 2001-2014 with the histogram of pixels in inset

The analysis examined the monthly burnt-area over the study period from 2001 to 2014 (Figure 2 ). It can be observed that the period between July to October has too low fire activity while the other months have higher fire activity. The analysis showed April as the month with the largest burnt-area during the study period. Comparing the pattern of burnt-area versus mean monthly precipitation and temperature provided a valid backup to the general understating on fires in Nepal. From June to August, the rainfall in Nepal is higher, thus the fire activity is lower. However, from November onwards, the average rainfall amount declines while the temperature starts to rise, providing suitable condition for fire to happen. The ecological explanation to this trend could be fuel accumulation following high vegetation growth during rainy season, followed by dry and hot periods making condition favorable for burning.

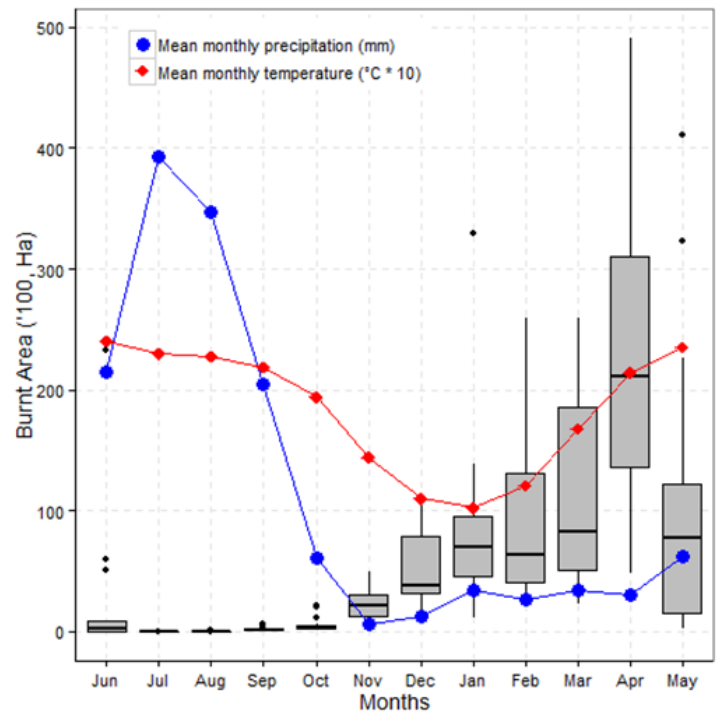

Fig. 2: Box-plot of burnt-area ('000 ha) by months, and mean monthly ppt. (mm) and temp. $\left({ }^{\circ} \mathrm{C} * 10\right)$

Annual burnt-area also varies distinctly with some years having much higher values as compared to others (Figure 3). On an average, during the study period, the mean burnt-area over Nepal is around 372,000 ha with the range of less than 163,000 ha to 760,000 ha. During the analysis period, 2001, 2009 and 2012 had the peak burntarea. Those years were reported to have high fire incidences in the news headlines. In 2012, more than 220 forest fire events were reported across Nepal (BBC, 2012). Similarly, NASA also reported large-scale forest fire in 2009 (NASA, 2009). While calculating the annual burnt-area, all the pixels burnt more than once in a calendar year were summed up to get the annual burntarea. Thus, there is some likely overlap, if an area experiences fire events more than once in a year.

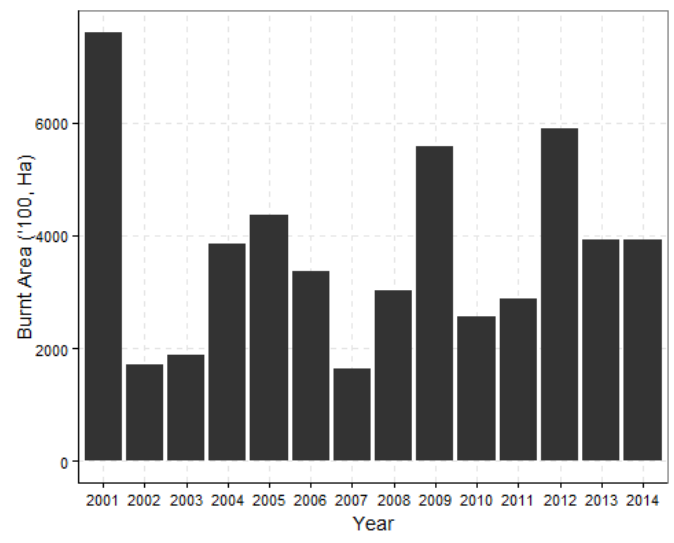

Fig. 3: Annual burnt-area (in ' 000 ha) during 2001-2014 
This study provided a general insight into spatiotemporal pattern of fire activity in Nepal, and attempted to relate the observed trends in the burnt-area with the climate data. Analysis of the number of times a pixel burnt as an indicator of spatial pattern of fire activity showed that the Western Nepal experienced more frequent fires. The burnt-area varied annually with some years having larger burnt-area. The monthly trend also varied during December- May experiencing larger fire activity with the peak in April. The comparison of the monthly burnt-area with the average precipitation and temperature conditions revealed the strong relationship of climatic variables with fire activity. Given the importance of understanding fire activity pattern over space and time for management intervention, future research should focus on providing more in-depth understating on fire regime in Nepal. This can be achieved by integrating observations from other satellites, validating MODIS burnt-area, using field data and including better climatological data in the analyses.

\section{References}

Bajracharya, K. M. 2001. Fire Situation in Nepal. In FRA Global forest fire assessment, 19902000 (ed) Goldammer, J. G., FAO, 2001.

BBC. 2012. More Than 220 Forest Fires Spread Across Nepal onApril26. British Broadcasting Corporation, London, UK. http://www.bbc. com/news/world-asia-17859358. Accessed on: 30th June, 2015.

Boschetti, L., Roy, D. and Hoffmann, A.A. 2009. MODIS Collection Five Burned Area Product-MCD45. User's Guide, Version 2.

Dwyer, E., Pinnock, S., Grégoire, J. M. and Pereira, J.M.C. 2000. Global spatial and temporal distribution of vegetation fire as determined from satellite observations. International Journal of Remote Sensing 21 (6-7): 1289-1302.

Giglio, L., Csiszar, I. and Justice, C. O. 2006. Global distribution and seasonality of active fires as observed with the Terra and Aqua Moderate Resolution Imaging Spectroradiometer (MODIS) sensors. Journal of Geophysical Research: Bio-geosciences (2005-2012) 111 (G2).
HMGN/MFSC. 2002. Nepal Biodiversity Strategy. Ministry of Forests and Soil Conservation, His Majesty Government of Nepal, Kathmandu, Nepal.

GoN/MFSC. 2010. Forest Fire Management Strategy 2010. Ministry of Forests and Soil Conservation, Government of Nepal, Kathmandu, Nepal.

GoN/MFSC. 2014. Nepal Biodiversity Strategy and Action Plan, 2014-2020. Government of Nepal, Ministry of Forests and Soil Conservation, Kathmandu, Nepal.

Hijmans, R J. 2015. Raster: Geographic Data Analysis and Modeling. R package version 2.3-40. http://CRAN.R-project.org/ package $=$ raster.

Hijmans, R.J., Cameron, S.E. Parra, J.L. Jones, P.G. and Jarvis, A. 2005. Very high-resolution interpolated climate surfaces for global land areas. International Journal of Climatology 25: 1965-1978.

Hurteau, M. D., Bradford, J. B., Fulé, P. Z., Taylor, A. H. and Martin, K. L. 2014. Climate change, fire management and ecological services in the South-western US. Forest Ecology and Management 327: 280-289.

Matteo Mattiuzzi, Verbesselt, J., Stevens F., Mosher S., Hengl, T., Klisch, A., Evans B. and Lobo A. 2013. MODIS: MODIS acquisition and processing package. $\mathrm{R}$ package version 0.10-9/r464. http://R-Forge.R-project.org/ projects/modis/. Accessed on: 30th June, 2015

GoN/MoE. 2010. National Adaptation Programme of Action to Climate Change. Ministry of Environment, Government of Nepal, Kathmandu, Nepal.

NASA. 2009. Forest Fires in Nepal. http:// earthobservatory.nasa.gov/NaturalHazards/ view.php?id $=37518$. Accessed on: 30 th June, 2015.

Pausas, J. G. and Keeley, J. E. 2009. A burning story: the role of fire in the history of life. BioScience 59 (7): 593-601.

R Core Team, 2013. R: A language and environment for statistical computing. In. 
Vienna, Austria: R Foundation for Statistical Computing.

Roy D. P., Lewis P., Schaaf C., Devadiga S., Boschetti L. (2006). The Global impact of cloud on the production of MODIS bi-directional reflectance model based composites for terrestrial monitoring. IEEE Geosci Remote Sens Lett 3 (4): 452-456.

Sharma, S. P. 2008. Wildland fires: Part IV Regional focus. CRISIS $\mid$ RESPO + NSE 4 (3): 54-55. 